\title{
Routine histological compared with immunohistological examination of bone marrow trephine biopsy specimens in disseminated neuroblastoma
}

\author{
M M Reid, J P Wallis, A G McGuckin, A D J Pearson, A J Malcolm
}

\begin{abstract}
The ability to detect infiltration in bone marrow biopsy specimens from patients with disseminated neuroblastoma was assessed by immunohistological and routine histological methods. Frozen cores from 33 staging procedures were tested with UJ13A and UJ127.11. Immunopositive tumour cells were found in 10 of 17 staging procedures in which tumour was detectable by routine histological methods. Positive cells or stromal material were also found in eight of 12 staging procedures in which distorted architecture and fibrosis, but no obvious tumour, had been noted. Paraffin wax embedded cores from 29 of the same staging procedures were tested with antibodies against neurone specific enolase and neurofilament. Only a single core reacted with anti-neurofilament antibody. Neurone specific enolase positive cells or stromal material were found in nine of 15 staging procedures in which obvious tumour was detectable. Although these immunohistochemical techniques proved inferior to routine histology in their ability to detect obvious tumour, the demonstration of immunopositive stromal tissue which was not frankly malignant supports the view that distorted, fibrotic marrow may reflect persistence of neuroectodermal tissue and justifies its distinction from normal marrow when reporting the response to treatment.
\end{abstract}

Department of

Haematology, Royal

Victoria Infirmary,

Newcastle upon Tyne,

NE1 4LP

$M M$ Reid

J P Wallis

Division of Pathology,

School of Pathological

Sciences, University of

Newcastle upon Tyne

A G McGuckin

A J Malcolm

Department of Child Health, University of Newcastle upon Tyne A D J Pearson

Correspondence to: Dr M M Reid

Accepted for publication

10 January 1991
Following the first description of the histological appearances of bone marrow infiltration with neuroblastoma, ${ }^{1}$ the difficulties in interpreting bone marrow appearances once treatment has started have been highlighted. ${ }^{2}$ Immunological detection of neuroectodermal tissue in sections of bone marrow is feasible, ${ }^{3-5}$ but the value of this approach remains largely untested. This report describes the comparison of routine histological examination with the results of immunohistochemical studies of bone marrow biopsy cores obtained either at diagnosis or as part of restaging procedures in a group of children with disseminated neuroblastoma.

The aims were, firstly, to discover whether immunostaining sections of marrow biopsy cores could reliably detect tumour in infiltrated marrow, secondly, to examine further the possibility that persistence of abnormal fibrous stroma indicates failure to eradicate tumour $^{2}$ and, finally, to assess the utility of immunohistology in the routine assessment of response to treatment of patients with disseminated neuroblastoma.

\section{Methods}

Marrow biopsy specimens from nine patients with disseminated neuroblastoma, aged 1-17 years, were examined. All had marrow infiltration at diagnosis. All were treated with intensive chemotherapy, two receiving the European Neuroblastoma Study Group regimen ENSG $3 \mathrm{C}^{6}$ and seven receiving experimental high dose rapid schedules. Two children with disseminated Ewing's sarcoma and two with acute lymphoblastic leukaemia (ALL), all of whom were known to have massive secondary marrow fibrosis at presentation, were also studied as examples of secondary fibrosis not due to neuroblastoma.

Bone marrow biopsy cores were obtained from iliac crests under a short general anaesthetic using a Jamshidi trephine biopsy needle. In the patients with neuroblastoma between two and four (mean three) iliac crests were biopsied at each staging procedure. Material from two to six (mean three) staging procedures was examined for each patient.

Biopsy specimens were taken from two iliac crests in the children with Ewing's sarcoma and from a single crest in those with ALL. Specimens were divided across their long axes into two roughly equal specimens of 0.5 to $2 \mathrm{~cm}$ in length. One half was placed into $10 \%$ neutral buffered formalin, decalcified with Gooding's and Stewart's medium, and embedded in paraffin wax. The other half was snap frozen as previously described ${ }^{5}$ and stored at $-70^{\circ} \mathrm{C}$ until required for testing.

The monoclonal antibodies UJ13A and UJ127.11, which react strongly with most neuroblastomas, ${ }^{7}$ were used for frozen section studies. Because both react with osteoblasts and occasional macrophage-like cells in normal marrow aspirates ${ }^{8}$ some care is needed when interpreting stained sections. A polyclonal antiserum against neurone specific enolase (Dako; No 4589) and a monoclonal antibody against the 200 kilodalton neurofilament peptide (Labsystems; No 6400500) were used to 
stain the paraffin wax embedded sections. Neither the monoclonal antibody Leu 7 nor antibody to S100, both of which may be of value in the diagnosis of neural tumours, were used because of their cross reactivity with haemopoietic cells. Leu 7 stains natural killer cells, and subsets of macrophages express S100.

Sections of the paraffin wax embedded material were stained with haematoxylin and eosin and by Foot's silver reticulin method.

Frozen sections were stained with UJ13A and UJ127.11 by a two-step immunoalkaline phosphatase technique as previously described. ${ }^{5}$ Sections of the paraffin wax embedded material were stained with antiserum against neurone specific enolase by a standard peroxidase anti-peroxidase (PAP) technique and, both before and after the addition of trypsin, with anti-neurofilament antibody by a standard indirect immunoperoxidase technique. Despite a preference for the colour reaction produced by an alkaline phosphatase label, previous experiments (data not shown) showed that, when staining the dewaxed, formalin fixed sections, the colour tended to fade. Therefore a peroxidase label was used when immunostaining this material.

\section{ASSESSMENT OF BIOPSY SPECIMENS}

Routine histological examination was carried out at the time of each staging procedure. Appearances in those with neuroblastoma were graded as previously described. ${ }^{2}$ Briefly, grade 1 described normal marrow (apart from cellularity); grade 2, marrow with increased reticulin as the only abnormality; grade 3, distorted architecture with fibrous tissue; and grade 4, marrow with obvious tumour cells, with or without the other abnormalities. The histological grades used in this study were taken from the original record made at the time of the staging procedure.

Immunostained slides were identified only by number. Each slide was examined independently by two observers (MMR and JW) for two features; the presence of immunopositive tumour cells and positively staining stroma. This latter feature consisted of positively stained extra-cellular collagen-like material, fibroblast-like cells, or other mononuclear cells amid fibrous tissue which could not be identified as frankly malignant or as osteoblasts. If either observer could not commit himself, or in the case of disagreement about either of these features, a joint review with a double-headed microscope was carried out. Positive controls of sections of appropriately handled tissue, frozen neuroblastoma for UJ13A and UJ127.11, and formalin fixed, decalcified nerve

Table 1 Comparison of routine histology with immunostaining using UJ13A and UJ127.11

\begin{tabular}{llllll}
\hline $\begin{array}{l}\text { Histology } \\
\text { grade }^{\star}\end{array}$ & $\begin{array}{l}\text { No of } \\
\text { staging } \\
\text { procedures }\end{array}$ & $\begin{array}{l}\text { Positive } \\
\text { tumour } \\
\text { alone }\end{array}$ & $\begin{array}{l}\text { Positive } \\
\text { stroma } \\
\text { alone }\end{array}$ & $\begin{array}{l}\text { Positive } \\
\text { tumour and } \\
\text { stroma }\end{array}$ & $\begin{array}{l}\text { Positive } \\
\text { neuroectodermal } \\
\text { tissue }\end{array}$ \\
\hline 4 & 17 & 2 & 3 & 8 & 13 \\
3 & 12 & 1 & 1 & 6 & 8 \\
2 & 2 & 0 & 0 & 0 & 0 \\
1 & 1 & 0 & 1 & 0 & 1 \\
\hline
\end{tabular}

^Grade 4 = obvious tumour; grade 3 = distorted architecture and fibrosis; grade 2 = increased reticulin alone; grade $1=$ "normal". and pancreas for anti-neurofilament and antineurone specific enolase antibodies, respectively, were included in each batch of tests. Negative controls, consisting of omission of the primary antibody, were included with the test slides from each core. After reporting and conferring was completed the number code was broken and results correlated with individual patients, sites, and dates.

If either positive tumour cells or stroma were found in any core then the final result of that staging procedure was recorded as "positive" for that feature. Inappropriate results in positive or negative controls, or excessive crush artefact in test slides rendered some of the material inevaluable. Only if no evaluable material was present in any of the cores stained with an individual antibody was a staging procedure called inevaluable.

\section{Results}

\section{UJ13A AND UJ127.11}

Ninety one frozen marrow cores from 33 staging procedures in the nine patients with neuroblastoma were tested together with 11 cores from six staging procedures in the four children with other malignant disease. Two hundred and four test slides were examined. Initial agreement between the two observers was achieved in $149(73 \%)$. Combined review was required in 55 . One staging procedure from a child with neuroblastoma and one from another with Ewing's sarcoma were not evaluable, leaving 32 evaluable staging procedures in the patients with neuroblastoma and five in the others.

In those with neuroblastoma there was broad similarity between results obtained with UJ13A and UJ127.11. On three occasions UJ13A alone detected tumour cells. A summary of the combined results of these two antibodies, together with routine histological appearances, is shown in table 1 . In only 10 of the 17 staging procedures in which tumour was detectable in the routinely processed material (grade 4) were immunopositive tumour cells detected. Immunopositive stromal tissue, however, was present in a further three sets of staging biopsy specimens in which immunopositive tumour cells had not been found. Immunopositive tumour cells were, however, found in seven of the 12 staging procedures, which by routine histological criteria, had grade 3 appearances, and positive stroma alone in a further one of these sets of specimens.

One child with Ewing's sarcoma had tumour cells which reacted with both antibodies and stromal tissue with UJ13A. No positivity was detected in either of the two children with ALL.

Examples of immunostained frozen sections have been published previously. ${ }^{5}$

\section{NEURONE SPECIFIC ENOLASE AND} NEUROFILAMENT

In the patients with neuroblastoma 109 formalin fixed, paraffin wax embedded cores obtained during 29 of the same 33 staging procedures described above were tested. Ten 
Table 2 Comparison of routine histology with immunostaining for neurone specific enolase

\begin{tabular}{llllll}
\hline $\begin{array}{l}\text { Histology } \\
\text { grade }^{\star}\end{array}$ & $\begin{array}{l}\text { No of } \\
\text { staging } \\
\text { procedures }\end{array}$ & $\begin{array}{l}\text { Positive } \\
\text { tumour } \\
\text { alone }\end{array}$ & $\begin{array}{l}\text { Positive } \\
\text { stroma } \\
\text { alone }\end{array}$ & $\begin{array}{l}\text { Positive } \\
\text { tumour and } \\
\text { stroma }\end{array}$ & $\begin{array}{l}\text { Positive } \\
\text { neuroectodermal } \\
\text { tissue }\end{array}$ \\
\hline 4 & 15 & 4 & 1 & 4 & 9 \\
3 & 9 & 0 & 0 & 0 & 0 \\
2 & 2 & 0 & 0 & 0 & 0 \\
1 & 1 & 0 & 0 & 0 & 0 \\
\hline
\end{tabular}

$\star$ Grade 4 = obvious tumour; grade 3 = distorted architecture and fibrosis; grade $2=$ increased reticulin alone; grade $1=$ "normal".

cores from six staging procedures in three of the four children with other malignant diseases were tested. The blocks from four of the staging procedures of those with neuroblastoma, one with ALL and one with Ewing's sarcoma were unavailable. Three hundred and fifty seven test slides were examined. Initial agreement between the two observers was reached in $322(90 \%)$. Combined review was required in 35 . Two of the 29 staging procedures from children with neuroblastoma were not evaluable.

Neurofilament was detected in only one of 238 cores despite satisfactory staining of positive control material. Further analysis is restricted to detection of neurone specific enolase. A summary of the results is shown in table 2. In only eight of the 15 staging procedures in which tumour was detectable in the routine histological preparations were tumour cells stained. Immunopositive stromal tissue was present in one other staging procedure. Thus some evidence of neuroectodermal tissue was found in nine of these 15 , but in none of the remaining 12 staging procedures. Neither the child with Ewing's sarcoma, nor that with ALL, had any neurone specific enolase positivity present in their biopsy specimens. Examples of immunopositive rosettes, small clumps of tumour cells, and stromal material are shown in figs 1-3.

\section{Discussion}

The international neuroblastoma response

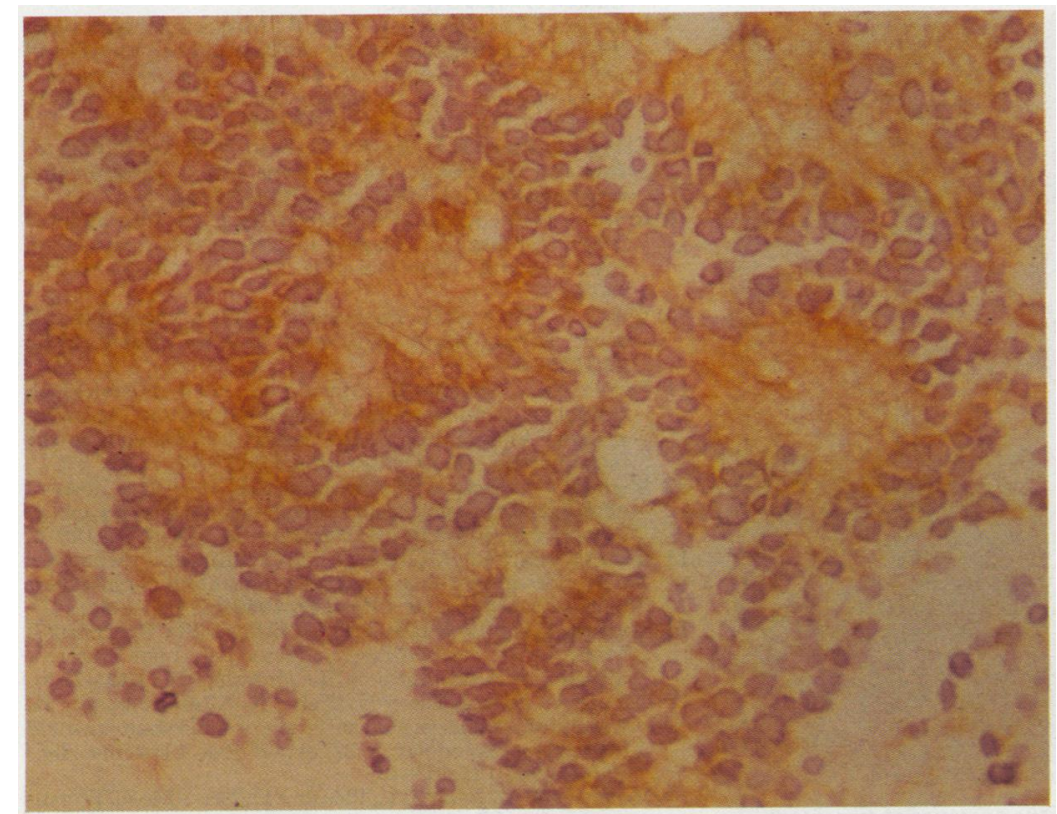

Figure 1 Positive staining in the centres of neuroblastoma rosettes. Bone marrow biopsy specimen at diagnosis (anti-neurone specific enolase; $P A P$ ). criteria ${ }^{9}$ require substantial efforts to assess what, in most cases, amounts to a variety of degrees of failure to eradicate tumour. A "tumour present/absent" grade for each marrow biopsy specimen is recorded. The natural tendency to seek hope in a partial response and the absence of a uniformly accepted histological definition of persisting disease may result in the temptation to equate absence of unequivocal tumour cells in a previously infiltrated marrow with "complete bone marrow response". The rarity with which the histological appearances of the marrow truly return to normal in disseminated neuroblastoma, however, is in sharp contrast to the speed and frequency with which they do so in diseases such as ALL. ${ }^{10}$ When this is coupled with the relentless rate of relapse, more critical appraisal of the marrow appearances in this disease is warranted.

There have been several reports of the use of monoclonal antibodies to neuroectodermal tissue to attempt to improve clinical staging and monitor response of bone marrow metastases to treatment in groups of children with disseminated neuroblastoma. ${ }^{41-14}$ In Newcastle upon Tyne immunocytochemical studies of native bone marrow smears, while of some value, did not match careful examination of bone marrow biopsy cores. ${ }^{8}$ It was felt that immunohistochemical techniques applied to the biopsy cores might provide important additional information and that their inclusion in the routine assessment of bone marrow response to treatment might be justified.

Two of the most promising monoclonal antibodies against neuroectodermal tissue, UJ13A and UJ127.11, are of no value in the study of formalin fixed tissue. They will detect neuroblastoma in alcohol fixed tissue ${ }^{14}$ or frozen sections ${ }^{5}$ of bone marrow, but morphology is not as well preserved by either approach as in formalin fixed tissue. Other antibodies such as those against neurone specific enolase and neurofilament can be used in formalin fixed tissue.

In only one marrow core of the entire series was neurofilament detected. The patient concerned was unusual in that he was an adolescent, had lived for over three years with detectable bone marrow infiltration and was the only patient in whom differentiation of tumour into forms resembling ganglion cells was seen in the marrow. Others suggest that neurofilament may be more easily detected in "mature" tumours than in primitive neuroblastomas, and that study of frozen material may be more rewarding. ${ }^{15} 16$

In general, neurone specific enolase was readily detectable only when the tumour load was great. The centres of Homer-Wright rosettes in such cases reacted strongly. In a few instances, however, stromal positivity, was clearly present in portions of the biopsy core which contained no obvious tumour.

On the other hand, UJ13A and UJ127.11 stained small foci of tumour cells, mononuclear cells with elongated, fibroblast-like nuclei, extra-cellular material and prolonged extrusions within areas of distorted architecture even in biopsies from staging procedures which by routine histological criteria did not 


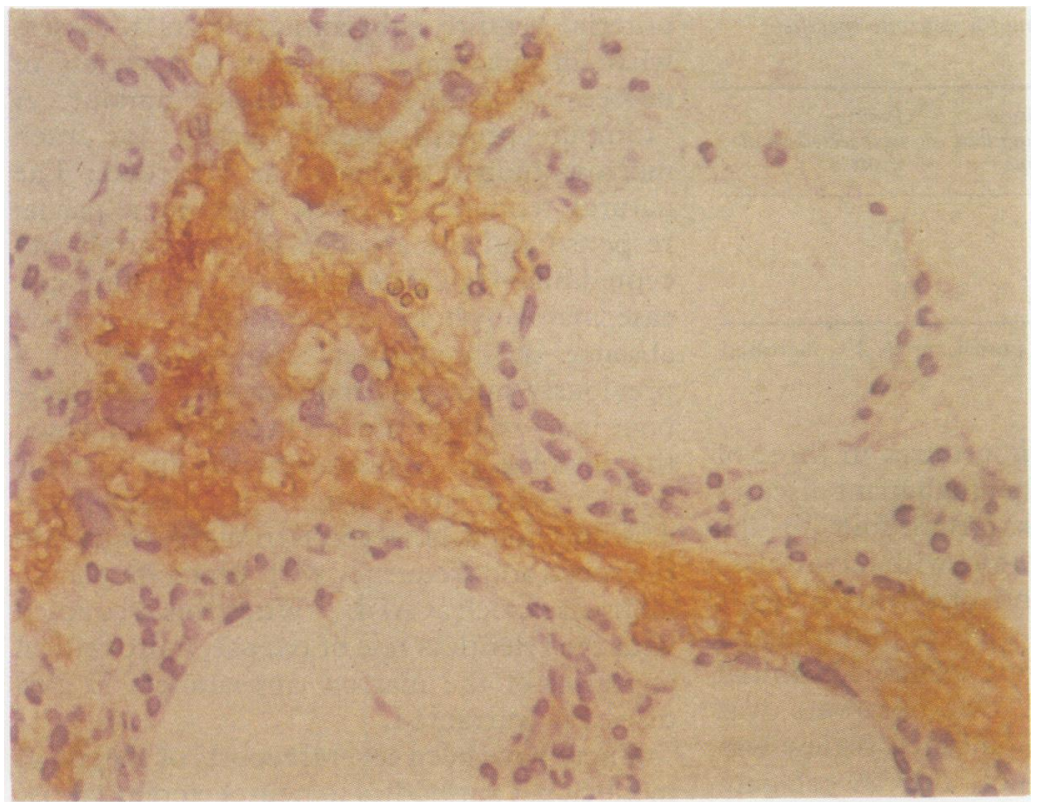

Figure 2 Small focus of tumour cells with associated immunopositive material. Bone marrow biopsy specimen after treatment (anti-neurone specific enolase; $P A P$ ).

contain obvious tumour. Nevertheless, these two antibodies failed to stain tumour in some cores which even the nuclear counterstain showed were heavily infiltrated.

None of the antibodies stained marrow cells or stromal tissue in the children with fibrotic ALL. Although we do not believe that reactive fibrosis per se is UJ13A or UJ127.11 immunopositive, appropriate control children with severe fibrosis secondary to conditions other than neuroblastoma are difficult to come by. Only one control child with Ewing's sarcoma, whose tumour cells aspirated from the marrow at diagnosis had been UJ13A and UJ127.11 positive, showed immunohistological reactions similar to those seen in neuroblastoma.

In conclusion, the results show that routine histological examination is better than these immunohistological techniques at detecting obvious infiltration. The association of immun-

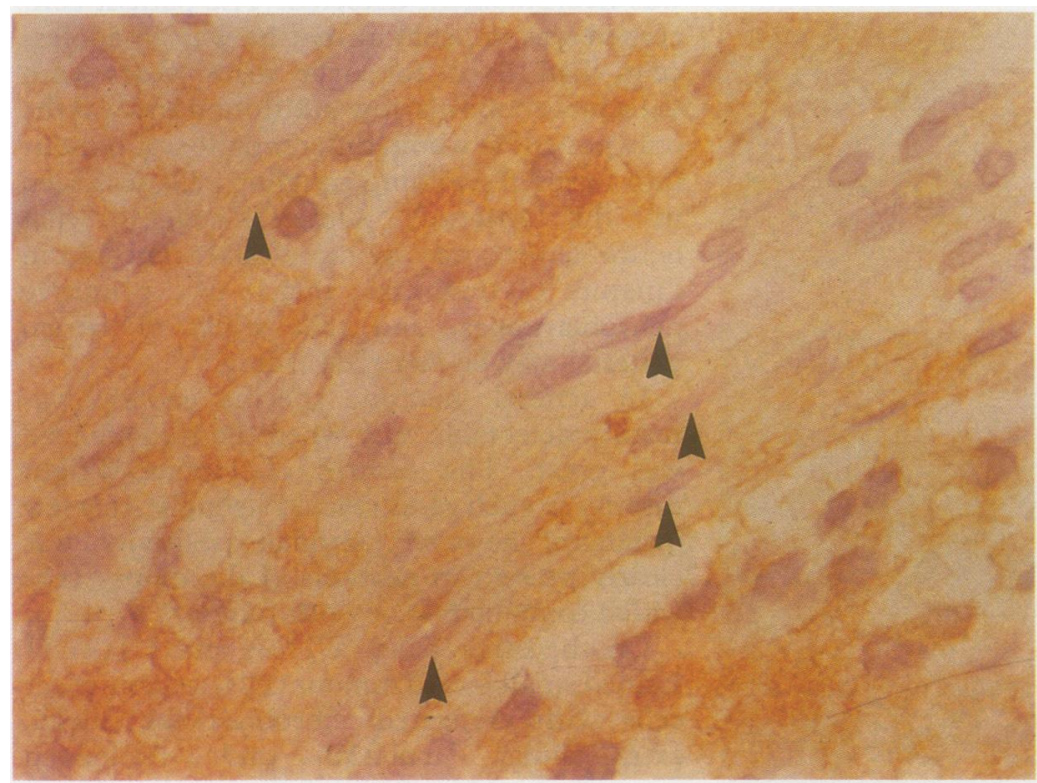

Figure 3 Positive staining of tumour cells and stroma. Note the presence of fibroblastlike cells (arrowed). Bone marrow biopsy specimen at relapse (anti-neurone specific enolase; $P A P)$. opositive cells with grade 3 histological appearances and immunopositive stroma with both grade 3 and grade 4 appearances reinforces our prejudice that the fibrotic appearances of the marrows of these patients may reflect at least two processes: firstly, a reaction of bone marrow fibroblasts to the presence of small numbers of occult neuroblasts and, secondly, that some of the apparently fibrous tissue may be a product of, or consist of, neuroectodermal tissue. Although these immunohistological approaches are valuable in research programmes, it is unlikely that they will find a place in the routine examination of marrow cores in this disease until antibodies to highly stable, formalin resistant, neuroectodermal antigens become widely available, or alternative handling of fixed biopsy specimens makes such investigations a more attractive proposition. In the meantime "service" will probably best be served by careful, routine histological examination of high quality biopsy cores. Whether distorted, fibrotic marrow (grade 3) is of prognostic or other clinical importance awaits prospective studies of large numbers of children, but there is already sufficient justification for distinguishing it from normal marrow when reporting the response to treatment.

We thank Dr J T Kemshead for donating UJ13A and UJ127 11 . A G M was supported by a grant from the North of England Children's Cancer Research fund, as were the running expenses for this project.

1 Mills AE, Bird AR. Bone marrow changes in neuroblastoma. Pediatr Pathol 1986;5:225-34.

2 Reid MM, Hamilton PJ. Histology of neuroblastoma involving bone marrow: the problem of detecting residual volving bone marrow: the problem of detecting residual tumour after initian

3 Ironside JW, Schiach CR, Cuthbert AC, Robinson EA. Histology of neuroblastoma involving bone marrow. $\mathrm{Br} J$ Haematol 1989;71:565-6.

4 Oppedal BR, Storm-Mathisen I, Kemshead JT, Brandtzaeg $P$. Bone marrow examination in neuroblastoma patients: a morphologic, immunocytochemical and immunohistochemical study. Hum Pathol 1989;20:800-5.

5 Reid MM, Malcolm AJ, McGuckin AG. Immunohistochemical detection of neuroblastoma in frozen sections of bone marrow biopsy specimens. J Clin Pathol 1990;43:334-6.

6 Pinkerton CR, Zucker JM, Hartmann O, et al. Short duration, high dose, alternating chemotherapy in metastatic neuroblastoma (ENSG $3 \mathrm{C}$ induction regimen). $\mathrm{Br} J$ Static neuroblastoma (EN

7 Kemshead JT, Clayton J, Patel K. Monoclonal antibodies used for the diagnosis of the small round cell tumours of used for the diagnosis of the small round cell tumours of childhood. In: Kemshead JT, ed. Pediatric tumours. Immunological and molecular mark

8 Carey PJ, Thomas L, Buckle G, Reid MM. Immunocytochemical examination of bone marrow in disseminated neuroblastoma. J Clin Pathol 1990;43:9-12.

9 Brodeur GM, Seeger RC, Barrett A, et al. International criteria for diagnosis, staging and response to treatment in patients with neuroblastoma. J Clin Oncol 1990;6: 1874-81.

10 Wallis JP, Reid MM. Bone marrow fibrosis in childhood acute lymphoblastic leukaemia. J Clin Pathol 1990; 42:1253-4.

11 Favrot MC, Frappaz D, Maritaz O, et al. Histological cytological and immunological analyses are complementary for the detection of neuroblastom
bone marrow. $B r J$ Cancer 1986;54:637-41.

12 Sugimoto T, Sawada T, Matsumura T, et al. Diagnosis of neuroblastoma metastasis in bone marrow with a panel of monoclonal antibodies. Med Pediatr Oncol 1988;16:190-6.

13 Beck D, Maritaz O, Gross N, et al. Immunocytochemical detection of neuroblastoma cells infiltrating clinical bone marrow samples. Eur J Paediatr 1988;147:609-12.

14 Rodgers DW, Treleaven JG, Kemshead JT, Pritchard J. Monoclonal antibodies for detecting bone marrow invasion by neuroblastoma. $J$ Clin Pathol 1989;42:422-6.

15 Osborn M, Dirk T, Kaser H, Weber K, Altmannsberger M Immunohistochemical localisation of neurofilaments and neuron-specific enolase in 29 cases of neuroblastoma. Am Pathol 1986;122:433-42.

16 Molenaar WM, Baker DL, Pleasure D, Lee VM-Y, Trojanowsky JQ. The neuroendocrine and neural profiles of neuroblastomas ganglioneuroblastomas and ganglioneuromas. Am J Pathol 1990;136:375-82. 